\title{
Arenas of Crisis
}

\section{Irene Strasser ${ }^{1}$ (D) Martin Dege ${ }^{2}$ D}

Published online:24 July 2021

(c) The Author(s), under exclusive licence to Springer Nature Switzerland AG 2021

Human Arenas has started a special section titled "Arena of Crisis," which will be published over several issues. In the special section, the authors discuss the relevance of crisis experiences. The articles approach the concept of crisis from four different perspectives. A first set of articles discusses community-related aspects, changes in the perception and usage of social media, and altered ways of relating to each other in times of lockdown and social distancing. The authors question concepts of normalcy that some hope to return to and examine new tensions that govern our daily life in uncertain times.

A second set of articles looks at digital technologies. Based on the apparent developments in digital technology during the pandemic and increased relevance of online interaction for some of us, these articles wonder if digital technology saved us from a complete halt of our social life during this pandemic. The authors examine how digital technology has changed our interactions and, with that, our social life in general.

A third set of articles focuses on questions of inequality during the pandemic. The authors examine how previously existing forms of discrimination have been elevated during the pandemic and how new forms of inequality have emerged or have come to the fore. As such, the authors in this section focus on intersections of gender, race, age, class in times of crises, and critical perspectives of decolonization.

A final set of articles try to understand the consequences of the Covid-19 pandemic for our construction of theory. The authors discuss how our understanding of ourselves, everyday life, and the social bond needs to change and how theorizing and critical practice be brought together can be brought together under changed and changing conditions.

Numbers, graphs, and statistics have dominated the news for almost 18 months now. While many of these contributed to transparency and a potentially better understanding of statistics and the spread of the pandemic, numbers tell us little about what happens in local communities on an individual and interpersonal level.

O'Connell and Lucić (2020), in their paper on scaffolding children's learning in a refugee shelter in Germany, try to shed more light on dealing with the pandemic and its consequences when it comes to learning support. The authors point out that the structure of education and housing systems for refugees in Germany generally contributes to more

Irene Strasser

irene.strasser@aau.at

Martin Dege

mdege@pratt.edu

1 Psychology Department, St. Bonaventure University, St. Bonaventure, NY, USA

2 Department of Social Sciences \& Cultural Studies, Pratt Institute, Brooklyn, NY, USA 
segregation than integration. They narrate the story of Oduman, an 11-year-old refugee from Afghanistan, and describe his individual journey. They point out the structural and systemic aspects that render his personal, unique story as related to common experiences in refugee camps. Focusing on the so-called Welcome Classes (preparation classes for nonGerman speakers), the authors report on a particular intervention carried out during the early pandemic and the school closures in more detail and discuss how this is embedded in socio-cultural theory (Vygotsky) and the framework of Pedagogies of Care. The paper outlines in detail how the circumstances of the pandemic and the specifics of life in shelters in Germany confront young refugees with a series of challenges, particularly when it comes to schooling and education. In a qualitative evaluation of the described Homework Mentorship Program, the authors show how students and learning support staff navigate this state of crisis towards more care and support in educational contexts.

How ways of thinking and collaborating during moments of crisis and contradiction are triggered is what Cripps Clark et al. (2020) describe. They examine how a Vygotskian community of scholars has developed in the Asia Pacific region over the past two decades and how this community seeks to respond to the current Covid-19 crisis. The authors refer to Cultural Historical Activity Theory-CHAT as an analytic tool and describe how joint reading and reflecting as a group of scholars led to developing a "theoretically informed praxis." Describing CHAT in more detail, the authors also relate the situatedness of the reading group, and its work during the pandemic, to the context of learning in Vygotsky's thinking. Specifically, how face-to-face, online, and hybrid models of interaction influence collaboration and thinking is further discussed in the paper.

In their paper on altered meanings of "home," Gezici Yalçın and Düzen (2021) talk about the "stay at home" catchphrase and other social distancing measures and how people's concepts of home changed during the pandemic. Home as space, both physically and imaginary, represents intimacy, privacy, belonging, but also loneliness and alienation, all of which are culturally shaped. The authors conducted a study in 15 different cities in Turkey and asked participants to reflect on their views of "home" before and during the lockdowns in spring 2020. The paper describes in detail how participants differentiate between home as physical space and the meaning of "home." The authors report that effects of social distancing were met with diverse strategies, such as expanding spaces, e.g., through communicating with neighbors over balconies or meeting in garden and terrace spaces or adapting to less interaction and more silence and time spent alone. In much detail, the authors report on the shifts participants underwent in experiencing the meaning of home before and during the lockdown, reconstructing home in different ways.

Blum's (2021) article discusses the phenomenon of inattentional blindness and our failures in perceiving change, particularly during times of crisis. She introduces the classical paradigm in studying blindness phenomena, as well as theoretical approaches on explaining these in the light of neurophysiological and psychological theories. Blum argues that we do perceive detail, but detailed perception might be limited to those aspects that were relevant before the changed circumstances due to a crisis, e.g., environmental change. The higher tendency to blindness may hinder both the perception of threat and potential solutions in a crisis.

New strategies in everyday life as a response to the pandemic "shock" and the measures put in place are at the center of Kalantidou's (2021) article. The author recapitulates the developments of the Covid-19 pandemic in early 2020 before questioning the concept of normalcy to which one could potentially turn back after the pandemic. Kalantidou renders normalcy as mainly reflecting norms and behaviors defined by discourses of efficiency and expenditure and asks how new strategies in daily lives are related to aspects of democracy 
and environmental practices. Consequently, the author discusses the divide between alternative governance models and grassroots claims for change and debates the concepts of risk society and risk culture. Finally, Kalantidou argues for more diverse strategies of governance of communities and bottom-up processes that are culturally embedded and provide more agency and self-reflection.

Particularly during the pandemic and the global lockdowns, it seemed evident, once more, that community is not bound to physical spaces and face-to-face interactions. Nandy (2021) takes a narrative perspective on social media and discusses how the self is constituted within virtual communities under the specific conditions of the Covid-19 crisis. The author points out as an essential characteristic of Facebook that it allows for the formation of virtual communities by generating content that can be shared with others. To show how a sense of community is developed, the author illustrates based on several recent examples how celebrity culture influences how Facebook users position themselves.

In his article on social media and the coronavirus, Johanssen (2020) discusses the idea of the world in a split state along the lines of healthy/unhealthy, vulnerable/non-vulnerable, safe/at risk, and others. According to the authors, these "splits" are reflected in social media posts and articles. He expands his analysis of this split state with the help of a Kleinian framework and Lacan's Discourse of the Hysteric.

In her article, Jarzyna (2020) talks about the concept of parasocial interactions as unidirectional relationships one forms with characters from the media industry (TV, social media). The author describes potential positive and negative outcomes and points out that particularly the Covid-19-related measures produced a shortfall of regular social interactions. The paper looks at parasocial interaction generally and under the condition of quarantine and lockdowns. Particularly, Jarzyna points out that typically parasocial interaction has been related to individual deficits in social interaction. In contrast, during the pandemic, we were confronted with an external, systemic lack of social interaction. The author also discusses whether parasocial interaction has positively affected feelings of togetherness during the pandemic.

Imamichi's (2021) article "Creativity in Crisis," discusses how we deal with the loss of social interactions in physical spaces. The shift to online modes of interaction has also introduced online teaching and distance learning. The author mainly investigates how we bend the former boundaries of technology usage and approach digital media creatively. Positioning themself as workers, educators, concerned citizens, and academic and environmental psychologists, the author explores how to navigate the new situation induced by the pandemic, in between the general technophobic dystopia and the necessity of criticizing surveillance. The paper specifically looks into how we can create a presence beyond the classroom by discussing the usage of YouTube videos.

Rai et al. (2021) explore Conceptual PlayWorld, a play-based intervention to support children's formation of STEM concepts. The authors argue that technology can be helpful to open up new perspectives for development, particularly when it comes to learning in the everyday world. In the same vein, technology is not at the center of Conceptual PlayWorld but rather a helpful tool. Discussing several examples and showcasing the activity settings, the authors discuss how this form of digital engagement in the early years can be used.

Mahendran et al. (2021) discuss how ideas of "home" have been dialogically constructed during the pandemic. Based on interviews conducted in England, Germany, Ireland, Scotland, and Sweden, the authors discuss negotiations of home beyond the common boundaries of space. Along the lines of national/transnational lines and intergenerational dialogue, the paper explores how such alternative concepts of home come together. Their study focuses on integration and citizenship and reveals interesting 
references to "home" connected to an understanding of home as involving concepts of the past, present, and future. Overall, the authors describe a process of homemaking that relates to intergenerational and transglobal dialogues instead of the simplified binaries populist leaders have used during the pandemic.

Cameron et al. (2021) discuss climate change and modern slavery as two of the most significant current crises. The authors picture a complex yet precise relationship between social inequalities, insecurity, and ecological crises. Specifically, they discuss the psychological consequences of the climate crisis that too often remain unseen: natural disasters triggering PTSD, depression, and anxiety disorders. The authors use the EPI (Environmental Performance Index), indicators of structural gender inequality provided by the United Nations, and the Global Slavery Index to perform a regression analysis. The data show evidence that certain factors for environmental change intensify social disparities.

Akpan (2020) explores how the Covid-19 pandemic is theorized as a point of change for former colonialized societies. Notably, he is looking at changes in religious practice, emphasizing the differences between Nigeria and the USA, using Piaget's concepts of accommodation and assimilation as a theoretical framework. Additionally, Akpan helps us question some terms and their implication to generalize in our global society, bringing our attention to what globalization means and what it brings to the two different parts of the world, particularly during the Covid-19 measures.

Urvashi (2020) discusses contemporary Indian higher education in light of the current Covid-19 pandemic. The author outlines the history of the Indian higher education system before discussing specifics of the current pandemic. Urvashi argues that universities generally are free spaces and contribute to democratization and equal opportunities; however, they are also embedded in systems of colonization. Finally, the paper explores specific policies and strategies and their potential future implication for the Indian educational system.

García (2020) takes her starting point at concepts of witnesses during the Spanish Civil War in order to analyze how, during the current crisis, individuals are confronted with the war rhetoric used to describe the virus and the pandemic. Taking a narrative perspective, the author explores how we went from narratives of the "crisis" to narratives of "war" during the ongoing pandemic by discussing examples from the media and the public discourse in Spain, one of the countries that reported high numbers of cases early on in 2020. "Combating" the virus in a battle, describing it as "the enemy," talking about the terror it evokes, are just a few of the rhetoric figures discussed. In critically discussing Western trauma theory, the author asks whether the generation of Spanish Civil War survivors has been confronted with re-traumatization due to old memories being triggered by the impacts of the pandemic and the war rhetoric in place.

Bansal (2021) critically discusses in her article the pandemic as socially and psychologically constructed rather than a simple consequence of a biological entity. Unconsciously, we develop signs of fear and anxiety, paranoia, prejudices, and guilt. The author aims to analyze the impact of the measures and asks whether individuals perceive the cure worse than the disease and how we picture a post-pandemic life. Is there a past normal we return to? Do we create a new normal instead? Can we transform our experiences of the pandemic into some form of learning and productive change?

Coming from a historical perspective, Jovanović (2021) explores the relationship between crisis and critique. The author renders the existence of crises as something diagnosed relatively often and argues that inequalities, politics using war metaphors, narratives of risk management, and controllability are reflections of general social crises. The paper discusses the role of psychology in theorizing crises and the use of the transformative power of critique and crisis. 
DuBose (2021) opens his contribution by discussing the myriad forms of pandemics and crises people have encountered throughout history. While usually referring to viral outbreaks when we talk about pandemics, DuBose argues that there could also be social, political, spiritual, pandemics, and so on. Focusing on the perception of everyday life phenomena, the author discusses the meaning and concept of hope.

Wasser (2020) discusses Heidegger's ethic of finitude and his work on technology and its relevance within the global pandemic. The author argues that we as human beings have a very limited behavioral repertoire that allows us to respond to the implacability of death. However, at the same time, we can live meaningful lives. The paper aims to discuss this in relation to the crisis on a general level and the current pandemic.

Croce (2021), in his article, relates to William James, starting with a discussion on how aspirational goals and ideals were developed at the Global Crises conference in May 2020. The author's aim is to provide ideas for the linkage of academic work and social issues. He follows three steps in his arguments and ends with a case study of how to practically apply ideals, using a Jamesian psychology framework.

\section{References}

Akpan, J. J. (2020). COVID-19: Harbinger of a new psychology of religion for postcolonial societies. Hu Arenas. https://doi.org/10.1007/s42087-020-00167-x

Bansal, P. (2021). The ravaged psyche: impact of the COVID-19 pandemic on the human mind. Hu Arenas. https://doi.org/10.1007/s42087-021-00190-6

Blum, S. (2021). Failure to perceive change: from neurons to social networks. Hu Arenas. https://doi.org/10. 1007/s42087-020-00180-0

Cameron, E. C., Hemingway, S. L., Cunningham, F. J., \& Jacquin, K. M. (2021). Global crises: gendered vulnerabilities of structural inequality, environmental performance, and modern slavery. Hu Arenas. https://doi.org/10.1007/s42087-020-00154-2

Cripps Clark, J., Jacobs, B., \& MacCallum, J. (2020). Solidarity and community: collaborative learning in times of crisis. Hu Arenas. https://doi.org/10.1007/s42087-020-00152-4

Croce, P. (2021). William James and the sustainable transformation of values, with a case study for rethinking the American Dream. Hu Arenas. https://doi.org/10.1007/s42087-020-00170-2

DuBose, T. (2021). Dum Spiro Spero: on post-pandemic hope. Hu Arenas. https://doi.org/10.1007/ s42087-020-00174-y

Gezici Yalçın, M., \& Düzen, N. E. (2021). Altered meanings of home before and during COVID-19 pandemic. Hu Arenas. https://doi.org/10.1007/s42087-021-00185-3

Imamichi, T. D. (2021). Creativity in crisis: a journey into YouTube. Hu Arenas. https://doi.org/10.1007/ s42087-021-00199-x

Jarzyna, C. L. (2020). Parasocial interaction, the COVID-19 quarantine, and Digital Age Media. Hu Arenas. https://doi.org/10.1007/s42087-020-00156-0

Johanssen, J. (2020). Social media and coronavirus: paranoid-schizoid technology and pandemic? Hu Arenas. https://doi.org/10.1007/s42087-020-00162-2

Jovanović, G. (2021). Subverted crisis and critique. Hu Arenas. https://doi.org/10.1007/s42087-020-00168-w

Kalantidou, E. (2021). Not going back to normal: designing psychologies toward environmental and social resilience. Hu Arenas. https://doi.org/10.1007/s42087-021-00198-y

García, A. B. M. (2020). Memories of war and the COVID-19 crisis in Spain. Hu Arenas. https://doi.org/10. 1007/s42087-020-00145-3.

Mahendran, K., English, A., \& Nieland, S. (2021). No obvious home: the public's dialogical creation of home during the third wave of decolonization. Hu Arenas. https://doi.org/10.1007/s42087-020-00176-w

Nandy, R. (2021). Facebook and the Covid-19 crisis: building solidarity through community feeling. $H u$ Arenas. https://doi.org/10.1007/s42087-020-00171-1

O'Connell, C., \& Lucić, L. (2020). An informal education intervention in response to the Covid-19 pandemic: homework mentorships in a Berlin refugee shelter. Hu Arenas. https://doi.org/10.1007/s42087-020-00161-3 
Rai, P., Fleer, M., \& Fragkiadaki, G. (2021). Theorising digital tools: mutual constitution of the person and digital in a conceptual PlayWorld. Hu Arenas. https://doi.org/10.1007/s42087-020-00178-8

Urvashi, S. (2020). Reimagining crises in the Indian university. Hu Arenas. https://doi.org/10.1007/ s42087-020-00160-4

Wasser, R. (2020). Crises, and the ethic of finitude. Hu Arenas. https://doi.org/10.1007/s42087-020-00142-6

Publisher's Note Springer Nature remains neutral with regard to jurisdictional claims in published maps and institutional affiliations. 